\title{
Teaching Medical Students How to Interpret Chest X-Rays: The Design and Development of an e-Learning Resource
}

This article was published in the following Dove Press journal:

Advances in Medical Education and Practice

\author{
Saif Sait $\mathbb{D}^{\prime}$ \\ Michal Tombs (D) ${ }^{2}$ \\ 'Postgraduate Medical \& Dental \\ Education Department, King's College \\ Hospital NHS Foundation Trust, London, \\ UK; ${ }^{2}$ Centre for Medical Education, \\ School of Medicine, Cardiff University, \\ Cardiff, Wales, UK
}

Introduction: The teaching of radiology to medical students has often been criticised for being inadequate and unstructured, with students reporting lack of confidence in assessing $\mathrm{x}$-rays. In this paper, we describe how an e-learning resource, on how to interpret a chest x-ray for medical students, was designed and developed. The aim of the resource was to provide medical students with knowledge of how to interpret a chest x-ray in a systematic approach.

Methods: The technology used to design the e-learning resource was Xerte Online Toolkits. The design and development of the e-learning resource was based upon andragogical principles and followed Overbaugh's guidelines and Mayer's 12 multimedia principles. An instructional design model called ADDIE was used to help develop the resource and its content. These included cases of common conditions, a quiz and summary table at the end. The paper focuses mainly on the way in which instructional design, education and multimedia principles were used to inform the development of the resource.

Findings: A preliminary evaluation was completed by 18 medical students from year 3-5 who completed the e-learning resource. The feedback was positive with an average rating of $9 / 10$ and $100 \%$ of students saying they would recommend the resource to a colleague. Students commented that they liked the resource as it was easy to navigate, had good visual learning and contained good explanations with relevant content.

Conclusion and Future Implications: This paper demonstrates how, with the use of instructional models, educational theories and principles, an e-learning resource can be created. Preliminary evaluation showed that students were satisfied with the resource and felt it helped them acquire knowledge on how to interpret chest x-rays. This resource can be further utilized either as a standalone resource or before starting clinical placements and may prove particularly useful in the current and challenging learning environment where there is an increased need for digital resources.

Keywords: instructional design, educational principles, learning outcomes, radiology, medical students, e-learning

\section{Introduction}

Radiology is one of the most rapidly growing medical specialties and every junior doctor must be competent in the systematic interpretation of basic imaging such as chest $\mathrm{X}$-rays. ${ }^{1,2}$ However, many medical students feel that radiology teaching is inadequate and unstructured, ${ }^{3}$ often reporting lack of confidence in assessing chest X-rays. ${ }^{4}$ The Royal College of Radiologist (RCR) recently published guidelines for medical schools on the undergraduate radiology curriculum. ${ }^{5}$ The RCR emphasised the need for medical students to recognise the normal structures as they appear on
Correspondence: Michal Tombs

Centre for Medical Education, School of Medicine, Cardiff University, Heath Park, Cardiff, Wales, CFI4 4YS, UK

Tel +44292068743

Email TombsM2@cardiff.ac.uk
Advances in Medical Education and Practice 2021:12 123-132 
imaging and on interpretation of basic imaging studies including chest x-rays, abdominal x-rays, skeletal x-rays, and computed tomography. For chest x-rays, the common conditions that medical students should know about include pneumothorax, pleural effusion, lung consolidation, heart failure and pneumoperitoneum. They should have a systematic approach in interpreting chest $\mathrm{x}$-rays and learn about common lines and tubes which may be seen.

Due to the COVID-19 pandemic, medical education across the world experienced a major disruptive change. ${ }^{6}$ In the United Kingdom, measures to ensure social distancing have included closure of medical schools, ceasing of clinical attachments, and medical students and educators working from home. As a consequence, technology has been rapidly and innovatively used to maintain teaching and learning. ${ }^{7}$ To provide medical students sufficient teaching, and to help medical educators maximize the use of time for teaching, an e-learning resource on how to interpret chest $\mathrm{x}$-rays was developed. It was thought that this could be used as a standalone e-learning resource or in conjunction with other teaching methods for medical students on how to interpret chest x-rays. ${ }^{8}$

Over the last few decades, there has been a shift in medical education leading to an increase in the use of e-learning resources to support and enhance the learning of medical students. ${ }^{9}$ Advantages of these resources include ease of access, flexibility for learners and greater amount of information. $^{10}$ Many medical students feel that it is a valuable way of learning, as it allows them to engage in an individualised learning environment. ${ }^{9}$ Moreover, e-learning has been shown to be at least as effective as traditional lecturing in many specialties, and across many stages of medical education. ${ }^{12,13}$ Indeed, there have been numerous examples of e-learning tools and concepts used in radiology to teach medical students in recent years. One of the most successful and widely used e-learning initiatives is radiopedia.org. ${ }^{14}$ This is a free online collaborative radiology resource that was compiled by radiologists and trainees from across the world. Since being set up in 2005, radiopedia.org has become one of the most trusted sources for health professionals and medical students and is used by individuals across the world. Another example was the development of an e-learning resource to teach positron emission tomography/computed tomography (PET/CT) to 139 undergraduate medical students. This was associated with a high degree of student satisfaction and $96 \%$ of students who took the e-learning resource passed their PET/CT exam station at the end of medical school. ${ }^{15,16}$
To maximise the learning and educational impact of any e-learning resources it is important to use well established and robust educational principles when designing it. ${ }^{11}$ This can sometimes be challenging, especially to those new to creating e-learning resources. ${ }^{8}$ Therefore, in this paper, we will explain how instructional design, educational and multimedia principles were used in the design and development of an e-learning resource on how to interpret chest $\mathrm{x}$-rays for medical students. The online resource can be accessed at https://xerte.cardiff.ac.uk/ play 11168. In line with the Royal College of Radiologists guidelines, ${ }^{5}$ the learning outcomes of the e-learning resource were written with the overarching aim of providing medical students with the knowledge on how to interpret a chest x-ray in a systematic manner (Box 1). In the paper, we also report preliminary evaluation of medical students' satisfaction of the e-learning resource and the impact this has had on their knowledge of how to interpret a chest $\mathrm{x}$-ray.

Box I Learning Outcomes of the e-Learning Resource

\begin{tabular}{|l|}
\hline Learning Outcomes \\
\hline By the end of the e-learning tutorial learners should be able to: \\
\hline - Assess systematically the quality of a chest radiograph \\
\hline - Apply a systematic approach for the interpretation of chest \\
radiograph \\
\hline - Detect common abnormalities seen on a chest radiograph \\
\hline
\end{tabular}

\section{Conceptual Framework: Learning Design and Development Principles}

The underpinning learning theory guiding the development of this e-learning resource was adult learning theory, or andragogy. ${ }^{28,29}$ In doing so, it considers medical students as adult learners who are likely to be more motivated to learn when the learning environment provides autonomy and flexibility, and when the learning activity is informed by constructivist principles. ${ }^{30}$ According to andragogical principles, learning is more likely to be achieved when the content of the resource is tailored to learners' needs, characteristics, and life context. ${ }^{28}$ An interactive, constructivist online learning environment, as opposed to a passive learning environment, has been found to help students learning more effectively. ${ }^{30}$ Accordingly, students are encouraged to actively engage in their learning. ${ }^{31}$ This can be through 
case-based scenarios, solving problems, and reflection. The way in which these educational and design principles were applied when developing the e-learning resource is described in detail below.

The design and development of this e-learning resource were based upon a range of instructional design, and multimedia principles. The ADDIE (Analysis, Design, Development, Implementation and Evaluation) model is commonly used amongst educators for designing and implementing educational resources. ${ }^{17}$ This is because it has clearly defined stages and a systematic approach that helps to organize the teaching content. However, the ADDIE model is not specific to e-learning, and therefore Overbaugh's guidelines, ${ }^{18}$ that look specifically at e-learning was utilised. Another drawback of ADDIE is that sometimes it can be too linear and systematic, and time consuming to implement. ${ }^{19}$ In light of this, Dick and Carey instructional design model, which is a modified version of the ADDIE model, was used in the design of this e-learning resource. This modified version of ADDIE focuses on constant re-evaluation and revision of the content through formative assessment. This allows the learners' needs to be at the centre of the e-learning resource. $^{20}$

Various frameworks and design principles were utilised to ensure that the resource was developed on the assumptions upon which adult learning theory is situated. With this in mind, a $\mathrm{PACT}^{21}$ (People, Activities, Context and Technologies) analysis was utilised to analyse the learners, their needs, and their requirements of the resource. Following the PACT analysis, clear learning outcomes were developed that informed the development of learning activities in the e-learning resource. When thinking about the action verb for the intended learning outcomes, Blooms Taxonomy was used. ${ }^{22,23}$ Several important design principles were used to design the resource and develop learning activities to maximise learning and ensure it is learner centred. The main guiding design principles were Mayer's 12 principles of multimedia. ${ }^{26}$ Overbaugh's guidelines for the development of computer-based learning was used which is based on Gagne (2005) nine learning events of instructional framework. ${ }^{18,27}$ The manner in which these principles informed the development of the resource will be embedded in the description of its content, activities, and design features.

\section{Methods - Putting Theory into Practice}

\section{Analysis of Needs}

In line with andragogical theory and the ADDIE model, the first stage of developing the e-resource required an analysis of the learners and their needs. A PACT (People, Activities, Context and Technologies) analysis ${ }^{21}$ was conducted through informal discussions with two medical students during their clinical placement. The students were asked about their preferred activities, which revealed that they would like to learn more about x-rays of common chest conditions. These discussions revealed that interpretation of a chest x-ray is often presented during the clinical placement and forms the basis of investigation for most patients that junior doctors will see on the wards and in the emergency department. However, the students we spoke with reported difficulties understanding and performing this task. In line with RCR requirements, it was therefore recognised that this group of learners have a specific need to understand how to systematically interpret a chest $\mathrm{x}$-ray. ${ }^{5}$ The medical students confirmed that the subject would be very relevant to their learning and it was established that the resource should be developed with all medical students attending a clinical placement in mind. These students should possess the pre-requisite anatomical knowledge and concepts relevant to the placement, but they lack content-specific terminology and concepts associated with chest $\mathrm{x}$ rays.

\section{Design Phase}

Once the target group of learners was identified, the second phase of the PACT analysis required consideration of the activities. However, before doing so it was essential to develop explicit learning outcomes that should inform the activities. The learning outcomes were therefore identified and written to reflect the radiology objectives with a focus on what medical students on clinical placement should gain upon completion of the e-resource (Box 1).

Following guidelines for the writing of good learning outcomes, they were designed to be Specific, Measurable, Achievable, Relevant and Timed (SMART). ${ }^{32}$ All the intended learning outcomes represented the higher cognitive domains in Blooms Taxonomy, as the aim of the e-learning resource is for the students to be able to interpret a chest x-ray that requires a deeper level of learning. ${ }^{22,23}$ They contain specific and active language 
and verbs such as assess, apply, and detect that make expectations clear and the standards by which they will be assessed (measurable). The learning outcomes also state what is likely to be achieved by completing the e-resource and are relevant for students at this stage of their studies (clinical placement in Radiology). The resource goes through a well-recognised and structured approach called ABCDE (Airway, Breathing, Cardiac, Diaphragm and Everything else) the students would be familiar with, so it places it in a relevant medical context. In addition, it contains six common cases that are in line with the common pathologies expected of medical students to be able to interpret. These are pulmonary consolidation, pleural effusion, pneumothorax, heart failure, pneumoperitoneum, and pulmonary embolism.

\section{Development of the e-Resource}

Learning activities are defined by Beetham (2007) as "a specific interaction of learner(s) with others using specific tools and resources, oriented towards a specific outcome". ${ }^{24}$ These are of primary importance when designing an e-learning resource. ${ }^{25}$ The activities were developed with the learning outcomes in mind and in a way in which learners' preferences were accommodated. More specifically, at the need analysis stage, students expressed a preference for an interactive, flexible tool that they could access as and when they need it.

Having considered the activities for the resource, we progressed to the third phase of the PACT model, which focuses on content. The content was created with the help of two radiology consultants who specialise in chest imaging. Additional materials were sourced from books, websites such as radiopedia.org, ${ }^{14}$ and online teaching resources. The e-learning resource takes approximately 20 minutes to complete. It has 19 slides included an initial slide on basics of chest x-ray anatomy, a systematic approach on how to review a chest x-ray, six common cases, a summary table and quiz. It is for continuous use but can be stopped and restarted at any point.

In the final phase of the PACT analysis, the technology is considered, and a decision was made to use Xerte Online Toolkits, which is free open source tool developed in 2009 for educational purposes. It was initially developed by Nottingham University but since 2014 Xerte is owned and managed by the Apero Foundation. ${ }^{33}$ Xerte allows the designer to achieve high level of interactivity and is also user friendly and suitable for those who do not have specialist Information
Technology (IT) knowledge or skills. Once published the learning resource can be edited by the author or others if required. Xerte Online Toolkits is accessed via a web browser using standards compliant HTML5 and can deliver material to both small screens and large desktop computers. This means the e-learning resource can be accessed from anywhere with internet access. ${ }^{34}$

During the development phase, a storyboard was initially created on PowerPoint before transferring this to the Xerte platform. ${ }^{35}$ Overbaugh's guidelines were used in conjunction with Mayer's (2005) 12 multimedia principles. $^{18,26}$ An initial slide on the basics of chest $\mathrm{x}$-ray anatomy (Figure 1) was used to gain attention and stimulate recall of the student's prior knowledge according to Gagne (2005) lesson framework and Mayer's pre training principle. ${ }^{26,27}$ This allows the learners to focus on a task to promote their learning and ensure they have the necessary prior knowledge.

In the next few slides, the e-learning resource goes through the important aspects of using a systematic approach for chest x-ray interpretation (Figures 2-5). Using Mayer's contiguity principles, the explanations were presented in words and pictures by using annotated chest $\mathrm{x}$-rays with words near the image to highlight the areas of focus (Figure 5). ${ }^{26,36}$ To prevent cognitive overload, ${ }^{37}$ Mayer's segmenting and signaling principle was used to highlight the aspects in different coloured sections, which allows the learner to compartmentalise the structure, and have different slides that covers technical aspects, quality and systematic

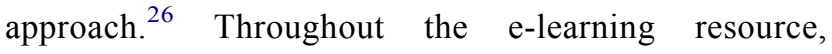
Mayer's coherence principle was used by keeping the content relevant and trying to limit the number of words per section (Figure 4). ${ }^{26}$ Mayer (2017) has shown that these principles are particularly important when students have little prior knowledge, such as the learners in the current setting. ${ }^{38}$

A summary table was added to reinforce what has been learnt. ${ }^{36}$ In slides $11-16$ (Figure 6) there are six cases that the student can work through and think about the approach they have learnt. These include common diagnoses such as pneumonia, pneumothorax, and pleural effusion. This is in line with what is expected for medical students as part of their curriculum. ${ }^{5}$ The cases help to highlight the importance of this subject in real life. Maier and Warren (2013) suggest that cased based learning can help represent the common conditions and aid deeper learning. ${ }^{39}$ By using several different principles and theories, the e-learning 


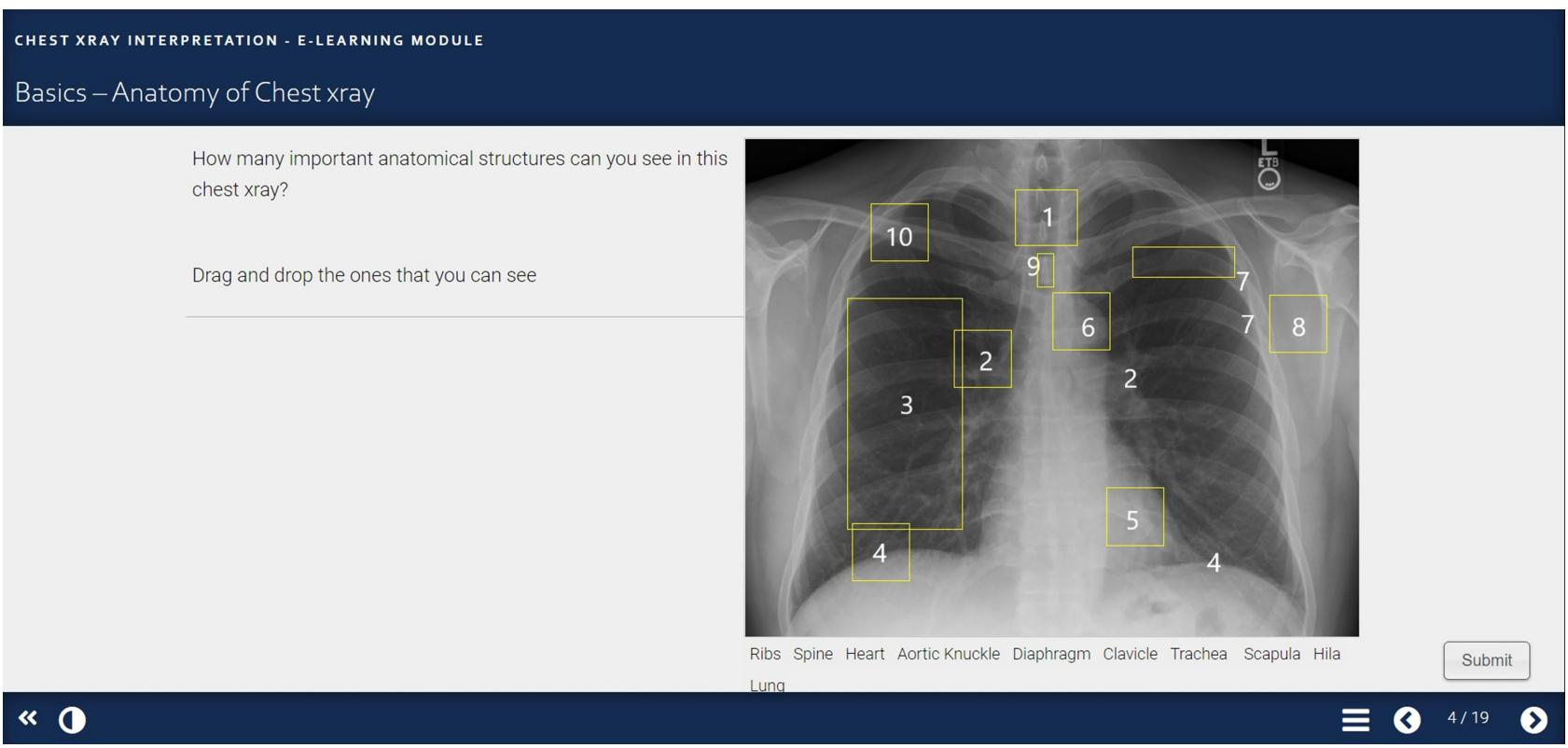

Figure I Basics - anatomy of chest x-ray slide. (I.Trachea, 2. Hila, 3. Lung, 4. Diaphragm, 5. Heart, 6. Aortic Knuckle, 7. Ribs, 8. Scapula, 9. Spine, I0. Clavicle).



Figure 2 Technical aspects slide.

resource aligns with the learning outcomes as it allows deeper learning and helps to re-enforce knowledge.

The final quiz (Figure 7) assesses learner's performance and if the learning outcomes have been met. There is instant feedback throughout the learning activities to help raise student's confidence, motivation and allow them to monitor their progress. ${ }^{8}$ The e-learning resource was completed with further reading for the learner that would assist in consolidating their knowledge gained.

\section{Findings - Implementation and Evaluation}

Following on from the development of the e-learning resource, the final two stages were implementation and evaluation. During the implementation phase, it was 


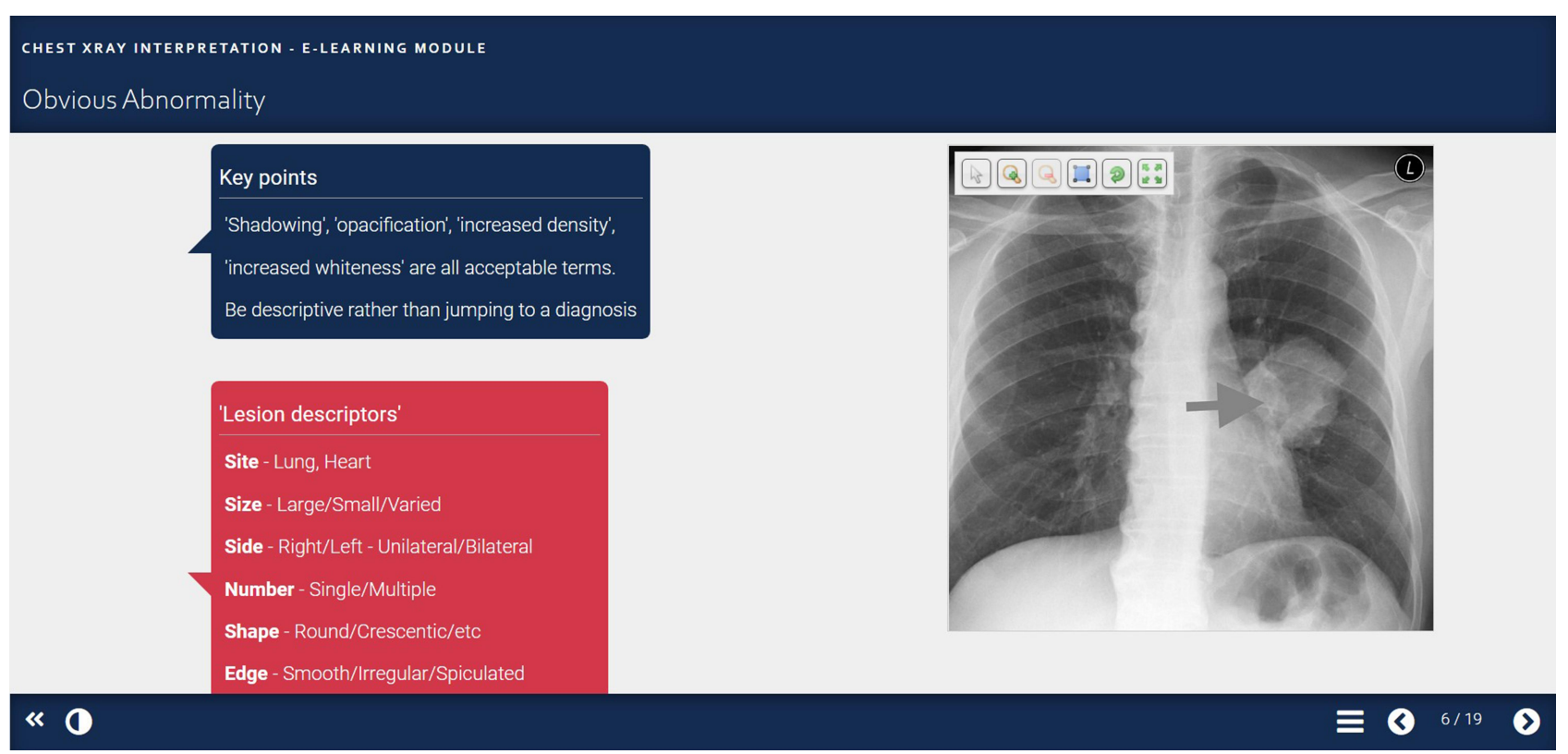

Figure 3 Obvious abnormality slide (arrow pointing at left lung mass).

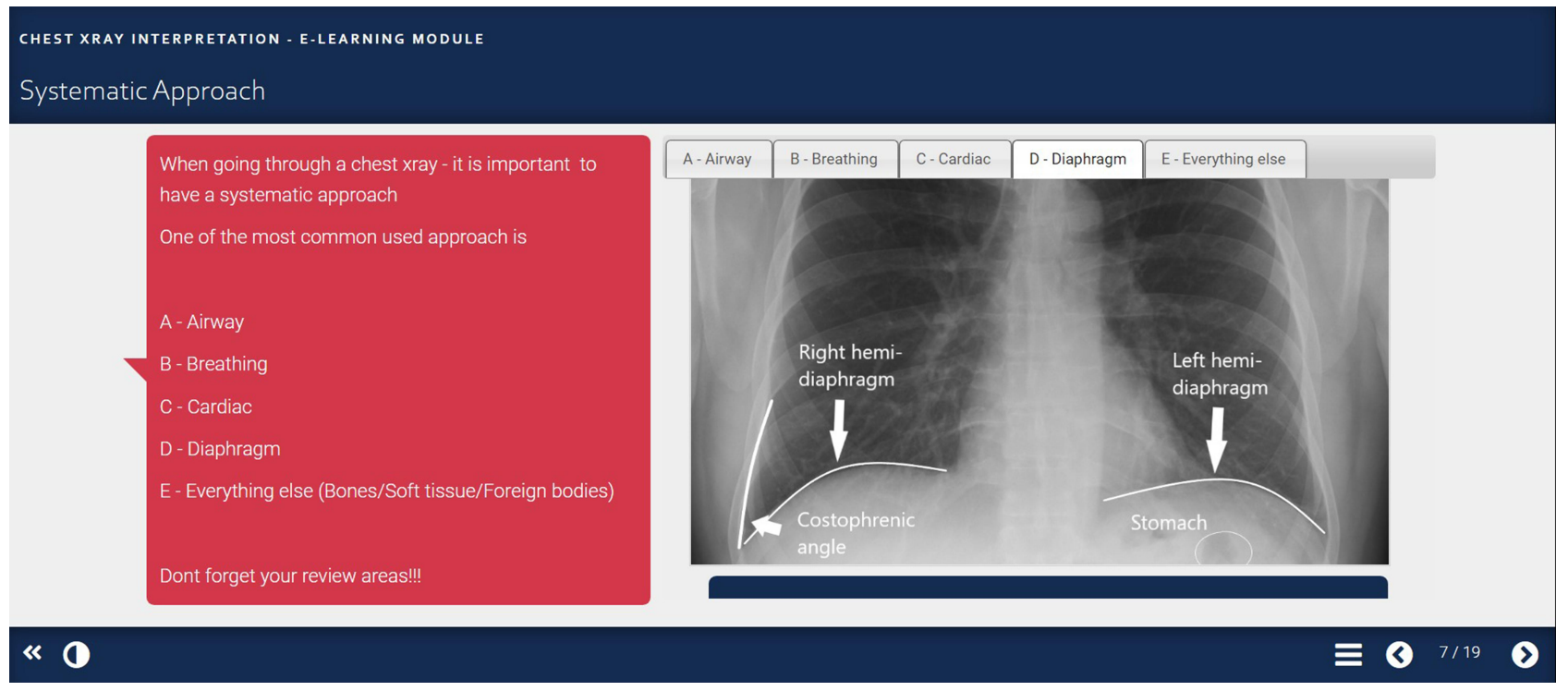

Figure 4 Systematic approach slide.

important to ensure that it had been designed and developed to be functional. Evaluation of the resource was done at different points throughout the process.

Following the storyboard phase, informal feedback was sought from the two radiology consultants who helped create the initial content for the e-learning resource. This was to make sure that the content was relevant and of high standard. An example of the feedback that was received included adding a script on how to present the chest $\mathrm{x}$-ray in an Objective Structured Clinical Examination (OSCE) format, which was subsequently added in the presenting section (see Figure 5). This showed the importance of gaining feedback at this stage which follows Dick and Carey's (2001) model. ${ }^{20}$

At the end of the e-learning resource a feedback form, adapted from Nesbit (2007), ${ }^{40}$ was added which the students could complete (Appendix). The feedback considered navigation, visual design, content and learning outcomes. There was also a question on rating the overall resource and if you would recommend the e-learning 


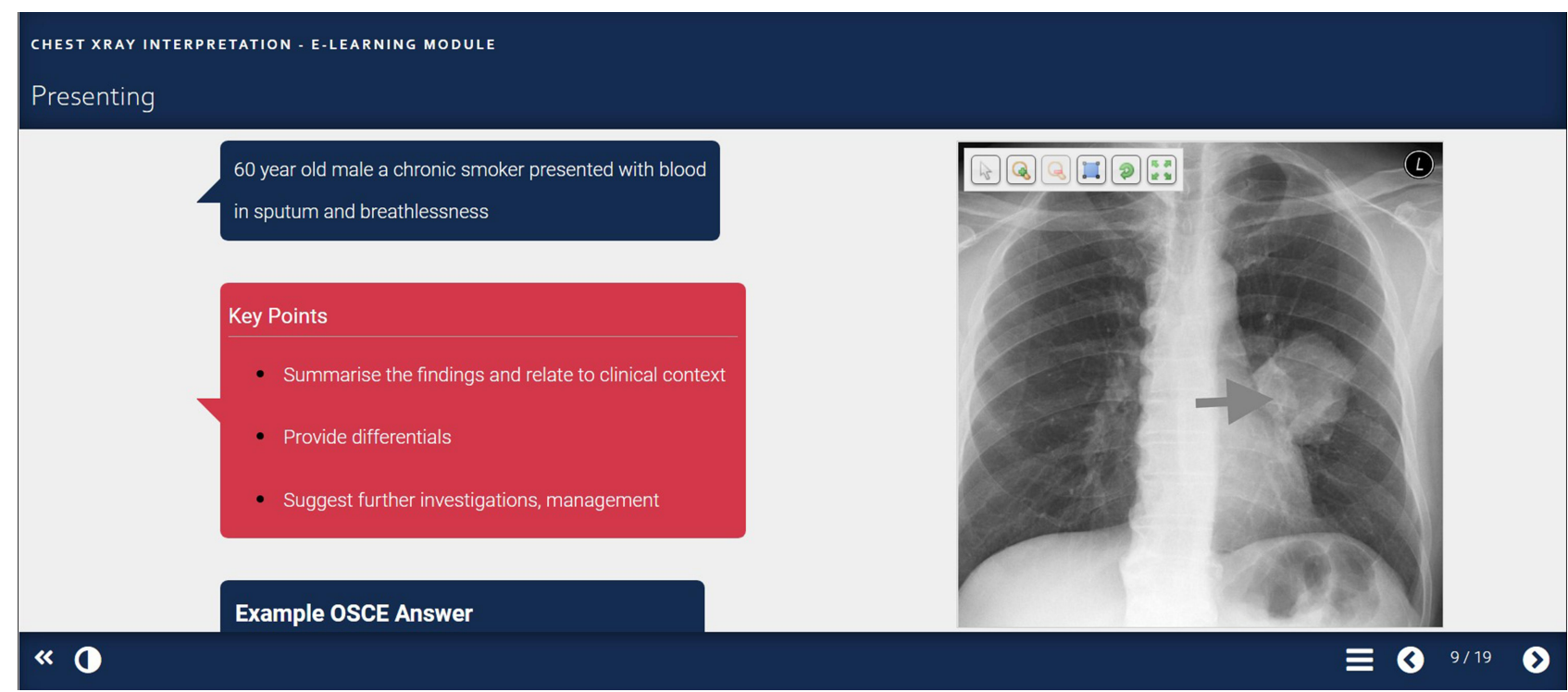

Figure 5 Presenting slide (arrow pointing at left lung mass).

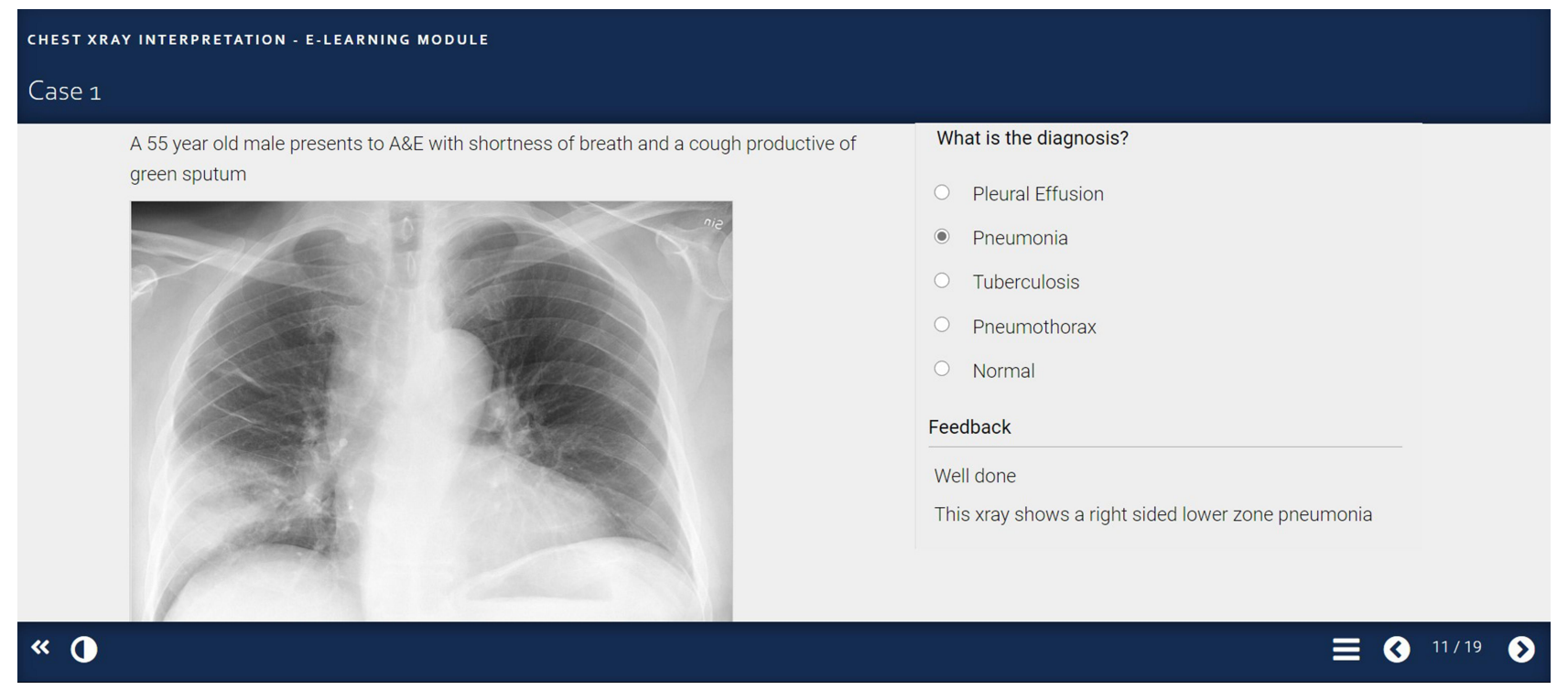

Figure 6 Cases slide.

resource to other medical students. Free text questions such as what was good about the e-learning resource, what could be improved, and any further comments were used. These can give a lot of information about what the learners thought was good and specific areas of improvement. $^{41}$

We disseminated the e-learning resource to medical students carrying out clinical placements at a busy hospital in the UK. Medical students were invited to complete the e-learning resource through email. As this was not a mandatory e-learning resource, 18 medical students from years 3-5 attending medical school at a UK
University completed the e-learning resource. The breakdown of how many medical students from each year completed the e-learning resource is shown in Figure 8. The feedback received was very positive (see Figure 9), with the average rating of 9 for the e-learning resource.

Ninety-four percent of learners agreed or strongly agreed that the learning outcomes were appropriate to their year of study, that the e-learning resource was easy to navigate, that the texts and graphics were of good quality, and that the content met the learning outcomes. All students said that they would recommend this e-learning resource to a colleague. Good aspects of the e-learning 


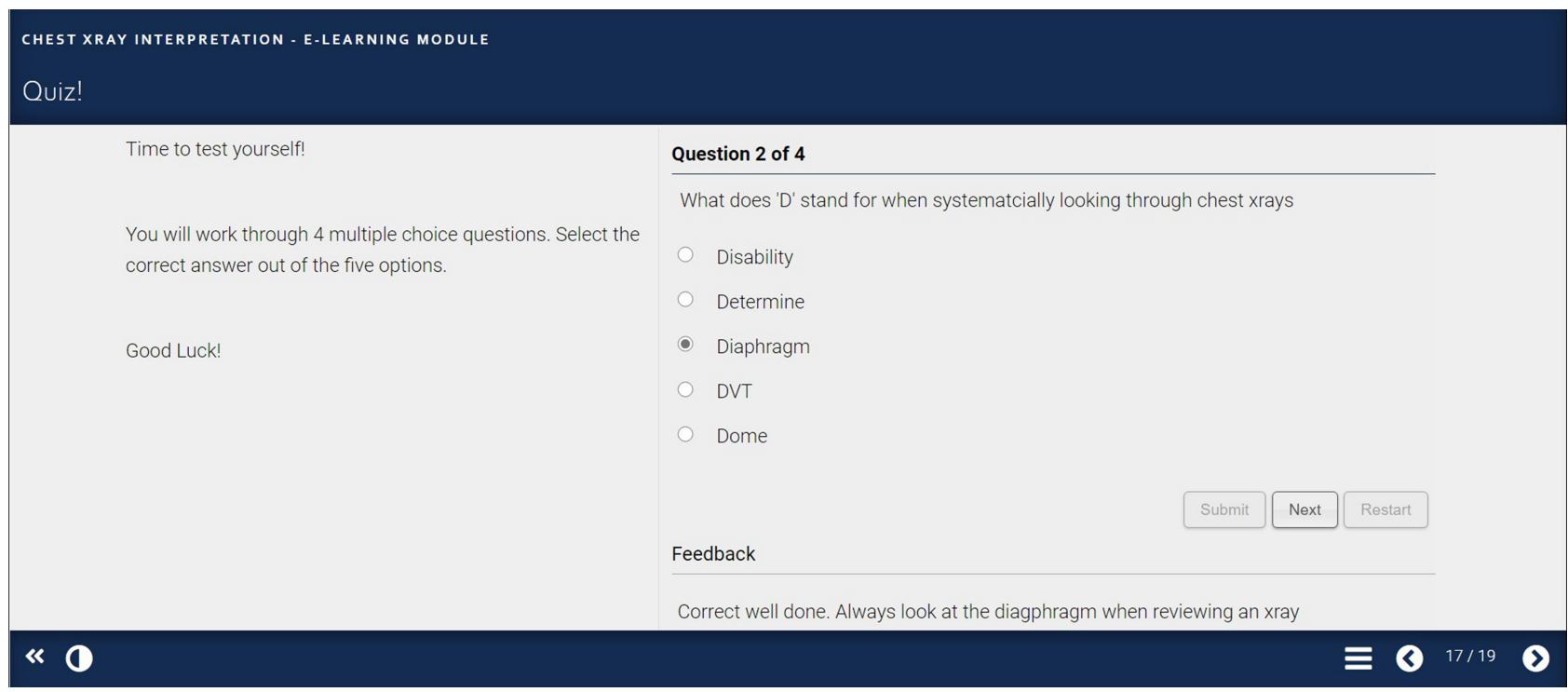

Figure 7 Quiz slide.

Year of medical student filling out e-learning resource

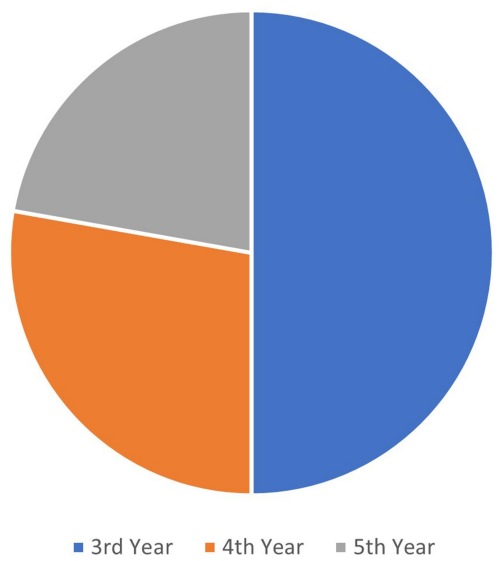

Figure 8 Year of medical students completing the e-learning resource.

resource that the students highlighted were, the resource being clearly structured and easy to navigate, good visual learning and thorough explanations with relevant content. The learners highlighted some areas on how it could be further improved, such as the quiz could be more challenging, and more chest $\mathrm{x}$-rays could be used to describe the diagnosis and pathology.

\section{Conclusion and Future Implications}

This paper describes the design and development of an e-learning resource for medical students on how to interpret chest $\mathrm{x}$-rays. It provides an example of how instructional models, educational theories and multimedia principles can be used to create an e-learning resource. ${ }^{17}$
In particular, the use of well-established theories and models helped to organise the content and create a learnercentred resource.

Preliminary evaluation showed that students were satisfied with the e-learning resource and felt it helped them acquire knowledge on how to interpret chest $\mathrm{x}$-rays. Even though the sample size was small, this was considered sufficient as it has been found that $95 \%$ of usability problems can be discovered in a sample of just five to six people. ${ }^{42}$ It must be noted, however, that this paper reports preliminary evaluation, and although positive, a more comprehensive evaluation is recommended to ascertain the impact and value of the tool. ${ }^{8,43}$ This could be expanded for example, by examining further and in-depth the long-term impact, change in behaviour and confidence in medical students with regards to chest $\mathrm{x}$-rays and attitudes towards the topic.

Despite it being a small-scale evaluation, the paper does provide a useful insight for those who want to consider developing e-learning resources. It reinforces the value of using well-established educational theories and design to help guide the process. The student satisfaction of this e-learning resource is similar to other radiology e-learning resources that showed high level of satisfaction among students. ${ }^{15,16}$ The COVID-19 pandemic has led to widespread disruption of medical education as a result of which medical schools have had to rapidly provide innovative approaches and alternative ways of teaching students core areas of medicine. ${ }^{6,44}$ These have led to the use 


\section{Student Feedback $(n=18)$}

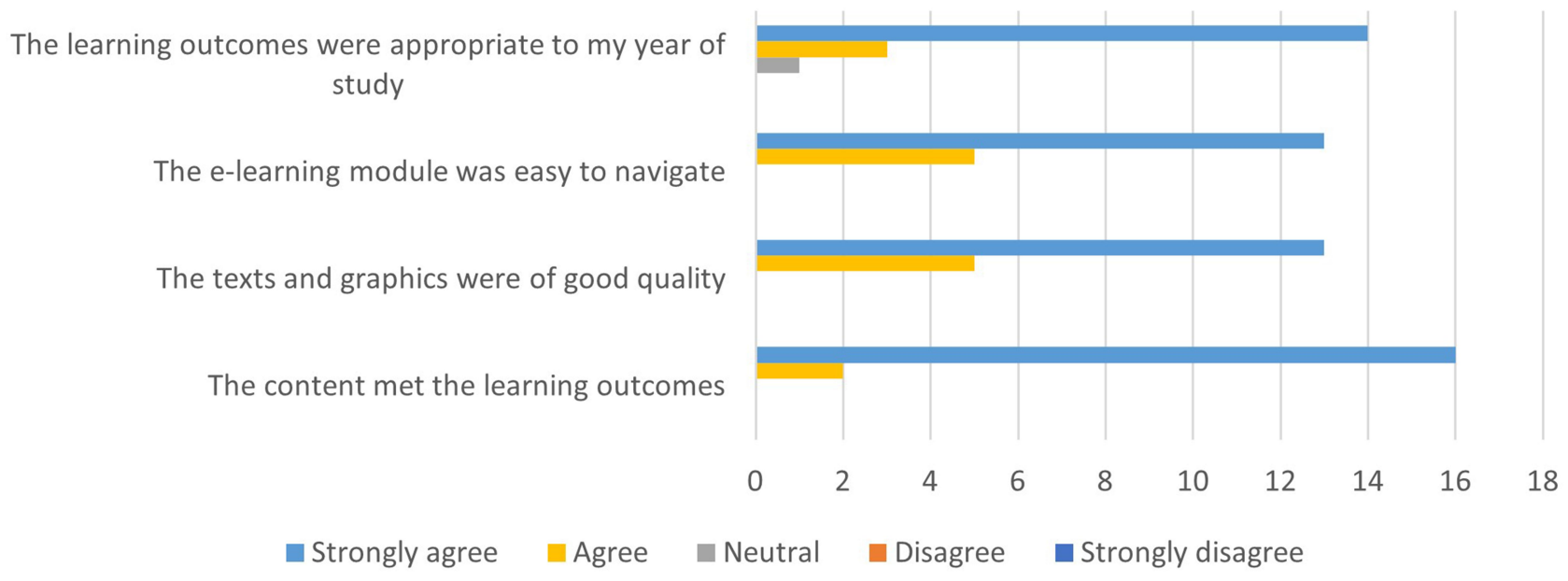

Figure 9 Results of feedback survey.

of webinars, online courses, and videos. ${ }^{45}$ This e-learning resource can be used as a stand-alone tool to increase medical student knowledge on how to interpret chest x-rays. The resource could also be used prior to medical students starting clinical placements and may give them more confidence in seeing patients and interpreting chest x-rays on the wards. ${ }^{4}$ Further e-learning resources on how to interpret common imaging modalities such as abdominal x-rays and computed tomography (CT) can also be developed which forms part of the medical students' undergraduate curriculum. ${ }^{5}$ It may also give medical students an insight into the role a radiologist plays and motivate them to explore radiology as a future career.

\section{Ethics Approval}

Ethical approval was not required as the evaluation of the online e-learning resource was a teaching activity and formed part of the resource development and not a formal research study. No personal data were collected.

\section{Disclosure}

The authors report no conflicts of interest in this work.

\section{References}

1. Council GM. Tomorrow's Doctors: Outcomes and Standards for Undergraduate Medical Education. Manchester, UK: General Medical Council; 2009.

2. Jacob J, Paul L, Hedges W, et al. Undergraduate radiology teaching in a UK medical school: a systematic evaluation of current practice. Clin Radiol. 2016;71(5):476-483. doi:10.1016/j.crad.2015.11.021
3. Nyhsen CM, Steinberg LJ, O'Connell JE. Undergraduate radiology teaching from the student's perspective. Insights Imaging. 2013;4 (1):103-109. doi:10.1007/s13244-012-0206-8

4. Satia I, Bashagha S, Bibi A, Ahmed R, Mellor S, Zaman F. Assessing the accuracy and certainty in interpreting chest X-rays in the medical division. Clin Med (Northfield Il). 2013;13(4):349. doi:10.7861/clinmedicine.13-4-349

5. Royal College of Radiologists. Undergraduate radiology curriculum (2nd ed). 2017. Available from: https://www.rcr.ac.uk/sites/default/ files/documents/undergraduate_radiology_curriculum_second_edi tion_2017.pdf. Accessed November 22, 2020.

6. Murphy B. COVID-19: how the virus is impacting medical schools. Amercian Medical Association. 2020. Available from: https://www. ama-assn.org/delivering-care/public-health/covid-19-how-virusimpacting-medical-schools. Accessed November 2, 2020.

7. Goh PS, Sandars J. A vision of the use of technology in medical education after the COVID-19 pandemic. MedEdPublish. 2020;26:9.

8. Salmon G, Tombs M, Surman K. Teaching medical students about Attention Deficit Hyperactivity Disorder (ADHD): the design and development of an E-learning resource. Advan Med Educ Pract. 2019;10:987. doi:10.2147/AMEP.S220390

9. O’Doherty D, Dromey M, Lougheed J, Hannigan A, Last J, McGrath D. Barriers and solutions to online learning in medical education - an integrative review. BMC Med Educ. 2018;18(1):130. doi:10.1186/s12909-018-1240-0

10. Mooney GA, Bligh JG. Information technology in medical education: current and future applications. Postgrad Med J. 1997;73 (865):701-704. doi:10.1136/pgmj.73.865.701

11. Chumley-Jones HS, Dobbie A, Alford CL. Web-based learning: sound educational method or hype? A review of the evaluation literature. Acad Med. 2002;77(10):S86-93. doi:10.1097/00001888200210001-00028

12. McGready J, Brookmeyer R. Evaluation of student outcomes in online vs campus biostatistics education in a graduate school of public health. Prev Med. 2013;56(2):142-144.

13. May L, Acquaviva KD, Dorfman A, Posey L. Medical student perceptions of self-paced, web-based electives: a descriptive study. Am J Distance Educ. 2009;23(4):212-223. doi:10.1080/0892364 0903332120

14. Gaillard F, Jones J. Collaborative radiology resources: radiopaedia. org as an example of a web 2.0 radiology resource. Am J Roentgenol. 2009;192:5. 
15. Gulati A, Schwarzlmüller T, Du Plessis E, Søfteland E, Gray R, Biermann M. Evaluation of a new e-learning framework for teaching nuclear medicine and radiology to undergraduate medical students. Acta Radiologica Open. 2019;8(7):2058460119860231. doi:10.1177/ 2058460119860231

16. Biermann M, Kanoun S, Davidsen T, Gray R. An open source solution for "Hands-on" teaching of PET/CT to medical students under the COVID-19 pandemic. Nuklearmedizin. 2020. doi:10. 1055/a-1267-9017

17. Allen WC. Overview and evolution of the ADDIE training system. Advan Develop Human Resources. 2006;8(4):430-441. doi:10.1177/ 1523422306292942

18. Overbaugh RC. based guidelines for computer-based instruction development. J Res Computing Educ. 1994;27(1):29-47. doi:10.10 80/08886504.1994.10782114

19. Kruse K Introduction to instructional design and the ADDIE model. 2002 Dec;26

20. Dick W, Carey L, Carey JO. The Systematic Design of Instruction (5th). New York: Longmann; 2001.

21. Benyon D. Chapter 2 - PACT: a framework for designing interactive system. In: Designing Interactive Systems: A Comprehensive Guide to HCI and Interaction Design. 3rd ed. Essex, England: Pearson Education Limited; 2013:26-48.

22. Bloom BS, Englehart MD, Furst EJ, Hill WH, Krathwohl DR. Taxonomy of Educational Objectives: Handbook I. Cognitive Domain. New York: David McKay; 1956.

23. Krathwohl DR. A revision of Bloom's taxonomy: an overview. Ilkögretim Online. 2009;8(3):1-7.

24. Beetham H, Sharpe R, editors. Rethinking Pedagogy for a Digital Age: Designing and Delivering e-Learning. Routledge; 2007.

25. Knight S. Effective Practice in a Digital Age. A Guide to TechnologyEnhanced Learning and Teaching. Higher Education Funding Council for England (HEFCE); 2009.

26. Mayer RE. Introduction to multimedia learning. Cambridge Handbook Multimedia Learning. 2005;15(2):1-24.

27. Gagne RM, Wager WW, Loals KC, Keller JM, Russell JD. Principles of instructional design. Performance Improvement. 2005;44 (2):44-46. doi:10.1002/pfi.4140440211

28. Knowles MS. The Adult Learner: A Neglected Species. 2nd ed. Houston, TX: Gulf; 1979.

29. Knowles MS, Holton III EF, Swanson RA. The Adult Learner: The Definitive Classic in Adult Education and Human Resource Development. Routledge; 2014.
30. Ruey S. A case study of constructivist instructional strategies for adult online learning. Br J Educ Technol. 2010;41(5):706-720. doi:10.1111/j.1467-8535.2009.00965.x

31. Palincsar AS. Social constructivist perspectives on teaching and learning. Ann Rev Psychol. 1998;49(1):345-375. doi:10.1146/ annurev.psych.49.1.345

32. Thomas PA, Kern DE, Hughes MT, Chen BY, editors. Curriculum Development for Medical Education: A Six-Step Approach. JHU Press; 2016.

33. Xerte Online Toolkits [homepage on the internet]. Nottingham: Nottingham University Available from: https:/www.nottingham.ac. uk/xerte. Accessed November 27, 2020.

34. Xerte Online Toolkits [Homepage on the Internet]. Cardiff: Cardiff University. Available from: https://xerte.cardiff.ac.uk/. Accessed 22 November, 2020.

35. Mifsud J Paper prototyping as a usability testing Technique. 2012 Available from: http://usabilitygeek.com/paper-prototyping-as -a-usability-testing-technique/. Accessed November 2, 2020.

36. Mayes T, De Freitas S. Learning and e-learning. Rethinking Pedagogy Digital Age. 2016;13-25.

37. Sweller J. Cognitive load theory, learning difficulty, and instructional design. Learning Instruction. 1994;4(4):295-312. doi:10.1016/09594752(94)90003-5

38. Mayer RE. Using multimedia for e-learning. J Comput Assist Learn. 2017;33(5):403-423. doi:10.1111/jcal.12197

39. Maier P, Warren A. Integr@ Ting Technology in Learning and Teaching. Routledge; 2013.

40. Nesbit J, Belfer K, Leacock T Learning object review instrument (LORI), Version 1.5. E-Learning Research and Assessment (eLera) and the Portal for Online Objects in Learning (POOL). 2007.

41. Artino AR Jr, La Rochelle JS, Dezee KJ, Gehlbach H. Developing questionnaires for educational research: AMEE Guide No. 87. Med Teach. 2014;36(6):463-474. doi:10.3109/0142159X.2014.889814

42. Nielsen J. Usability Engineering. Morgan Kaufmann; 1994.

43. Kirkpatrick D, Kirkpatrick J. Evaluating Training Programs: The Four Levels. Berrett-Koehler Publishers; 2006.

44. Ahmed H, Allaf M, Elghazaly H. COVID-19 and medical education. Lancet Infect Dis. 2020;20(7):777-778. doi:10.1016/S1473-3099(20) 30226-7

45. Dong C, Goh PS. Twelve tips for the effective use of videos in medical education. Med Teach. 2015;37(2):140-145. doi:10.3109/ 0142159X.2014.943709
Advances in Medical Education and Practice

\section{Publish your work in this journal}

Advances in Medical Education and Practice is an international, peerreviewed, open access journal that aims to present and publish research on Medical Education covering medical, dental, nursing and allied health care professional education. The journal covers undergraduate education, postgraduate training and continuing medical education including emerging trends and innovative models linking education, research, and health care services. The manuscript management system is completely online and includes a very quick and fair peer-review system. Visit http://www.dovepress.com/testimonials.php to read real quotes from published authors. 